\title{
Citizen Engagement: Driving Force of E- Society Development
}

\author{
Xiaolin Qiu \\ School of Information Management Wuhan University, Wuhan, China \\ 430072
}

\begin{abstract}
Starting from the belief that e-inclusion should be the strategic choice, and full engagement of every citizen is the key to the success and healthy development of e-society, this paper puts forward that "Information Commons" model can be applied to a larger target group: the disadvantaged citizens for their information rights and e-literacy education. Three IC applications: residents' community IC, public library IC, and government agency IC are discussed.
\end{abstract}

\section{Introduction}

This paper presents the views of the author in relation to e-inclusion as a very important strategy of e-society. The author believes e-inclusion will eliminate digital divide which checks the healthy development of e-government, e-commerce, and e-learning, significant indicators of e-society.

Research on e-inclusion shows that there has been a cry for information equality and great efforts have been made such as Open Access Movement, information literacy education, and e-learning initiatives. However, the research mainly remains in the academic community, higher education, high schools and a few primary schools. Research on grass roots citizens is scarce. To address this gap, this paper focuses on measures promoting ordinary citizens' information rights, information literacy education, and information usage leading to the full engagement into e-society.

The paper discusses, as specific measures of promoting citizen engagement into e-society, the information commons model at residents' community level, public library level, and government agent level. Next steps are briefly described.

Please use the following format when citing this chapter:

Qui, X., 2007, in IFIP International Fedcration for Information Processing, Volume 252, Intcgration and Innovation Orient to E-Society Volume 2, eds. Wang. W., (Boston: Springer), pp. 540-548. 


\section{Background}

An information society, or knowledge-based economy, is one in which people's lives, business operations, and government decision makings etc. are greatly improved and impacted by quantity, quality and speed of their information aquiring, processing and using. With wide applications of ICT, e-government, ecommerce and e-learning are becoming important indicators of a country's comprehensive competitiveness and national strength. Information resources have become pillar resources for economic development. Information society is seen as the successor to industrial society and draws its growth from the forces of globalization (through its intensive investment forces, cultural influence and unification of the market), knowledge intensity (over $70 \%$ of the workers in the developed world are knowledge/information workers), connectivity (internet, mobile networks, advanced interactive applications) [1]

\subsection{E-government an achievement of e-society}

With ICT, and especially the Internet technology, governments around the world can deliver online government information and services to citizens, business, and other government agencies. Public sectors' performance is evaluated with indexes like "Efficiency, Effectiveness, Economy, and Equity". Up to now, more than $90 \%$ of local governments have established one-stop portals in China. [2] "Government Online Project", "The Golden Projects", "Business Online Project", and "Family Oniine Project" have made great achievements in promoting e-society's development. China e-government ranked the $12^{\text {th }}$ in 2003 among 198 countries around the world. [3]

According to the study undertaken in AUG. 2000, which was sponsored by the Council for Excellence in Government about public attitudes toward and use of e-government in the US, more than two-thirds of adult e-government users gave public agencies high marks for their websites. $71 \%$ believed that the quality of government websites they had visited was excellent or good, $26 \%$ felt they were only fair, $2 \%$ rated them poor, and $1 \%$ was unsure. [4] Generally people think egovernment makes government more accountable and more transparent, more efficient and cost-effective, provides greater access to government information, and makes government service more convenient.

\section{2 "Digital divide" the greatest concern of e-society}

Digital divide, the gap between the information-haves and information-have nots, is the major concern for each and every country in the world. The gap exists between rich people and poor ones in the traditional sense within a certain country, and it also does exist between developed and developing countries. Survey results show that more than half of the Internet users are young male with higher income and better education (also a result of being rich). A majority of non-users of the Internet are either poor being unable to afford a computer and access fees, or short of necessary Internet and information skills. Economic wealth and the level of 
R\&D spending were the best predictors of Internet usage (Pippa Norris). [5] Countries that were wealthy and had a competitive market structure feature higher levels of connectivity. (Eazter Hargittai) [6] Economic wealth and digital access costs mattered more than market structure or regulatory approach. (Sampsa Kiiski and Matti Pohjola) [7] Globally, special-needs populations are not receiving much help in terms of accessibility. [8]

Even in the US, one of the most advanced countries in e-government development, half to two-thirds of the adult population remain outside the world of digital government, [9] let alone the developing countries. The negative impact of the paucity of e-government users is the difficulty in reaching the economy of scale which lowers per-unit costs. Lack of engagement by most of the people widens the digital divide, causes potential conflicts and dissatisfaction among people. People's negative opinion about the technology limits the technological diffusion in government agencies. Lack of most citizen engagement loses the win-win benefit of e-government that makes government officials be more responsive to ordinary citizens, and the general public more supportive to the government. E-government will not produce a major transformation in citizen usage as long as most people do not access government websites.

\section{Related Literature Review}

\subsection{Open Access Movement}

Many initiatives have been made in academic community as far as equality in the access and use of research results is concerned. Budapest Open Access Initiative in 2002 starts the OA Movement, which has got a lot of supporting voices from OECD, IFLA, Wellcome Trust, UN, and ACRL etc. etc. [10] The most recent one comes in January, 2007, five leading European research institutions launched a petition that called on the European Commission to establish a new policy to require that all government-funded research be made available to the public shortly after publication. Within weeks, it garnered more than 20,000 signatures, including several Nobel Prize winners and more than 750 education, research, and cultural organizations from around the world. [11]

The open access principle is that the published output of scientific research should be available on the public Internet, without change, to EVERYONE, "not merely among those who can attend the daily lectures - but far and wide."(Daniel Coit Gilman). The Directory of Open Access Journals, a Swedish project that links to open access journals in all disciplines, currently lists more than 2,500 open access journals worldwide featuring over 127,000 articles. [12]

\subsection{Information Literacy Education}

Information literacy education has long been a great concern in developed countries like United States. They connect the inability to master and apply new 
technologies with "mediocrity that threatens our very future as a nation and a people" facing ever increasing competition in the global economy. [13] So, many initiatives concerning information literacy education and e-learning have been going on. Seven U. S. states such as Virginia, New Mexico, Louisiana, etc. have their own education programs. For instance, Pennsylvania received a $\$ 1.8$ million grant from the U.S. Department of Education to study the impact of computers on student achievement. Arkansas' Environmental and Spatial Technology Initiative includes strong relationship between business, government and education, providing awareness and access to resources normally not available to educators. [14]

\subsection{E-Learning}

Since 2000, there has been an explosive growth in e-learning and virtual schools in America, making it possible for students at all levels to receive high quality supplemental or full courses of instructions personalized to their needs. In higher education, some $90 \%$ of four-public institutions and more than half of four-year private institutions offer some form on online education, by providing every student access to e-learning, and by enabling every teacher to participate in elearning training. A teacher from a small, rural Florida District said: "Online learning "evens the playing field' for rural students." "No Child Left Behind Act" passed in 2001 was signed into law by U.S. President Bush in January 2002. The goals are to end the achievement gap between rich and poor and white and minority students, and improve the academic performance of all students by 2014 . The US Department of Education is promoting the value of broadband and other technologies for lifelong learning. Broadband technologies have great educational value as well as far-reaching economic impact and on March 26, 2004, President Bush announced a major broadband initiative with the goal of connecting every home to broadband by 2007. [15]

\section{Concept Basis and Research Focus}

\section{1 "E-inclusion" Choice of E-society}

E-society consisting of e-governance, e-commerce, and e-learning forms the foundation of a nation's competitiveness. Social divide weakens a nation's competitive strength. Social divide is not a direct result of e-society, but a phenomenon that has long been preexisting. Poverty and backwardness caused by scarcity of natural resources, geographical limitations, different historical and cultural background, and unsuitable economic systems, etc. existed within one country as well as between countries. New forms of social divide we are facing today: "Digital divide" or "technological divide", which are directly relevant to the above factors though, are more serious and more strongly concerned by more and more people around the world. Because "Digital divide" can either deteriorate the 
already worse situation of polarization between the rich and the poor, or have it improved and eliminated. The choice of e-society for each and every country should be "e-inclusion" to turn the risk of a digital divide into "digital cohesion" and "digital opportunities", by bringing the benefit of the Information Society into all segments of the population, including: people who are disadvantaged due to education, ageing, limited resources, gender, ethnicity, people with disabilities, geographical digital divide. [16]

\subsection{Research Focus}

Embracing the strategy of e-inclusion and emphasizing "outreach" and "responsiveness" of e-government services, the paper focuses on the measures promoting grass-root citizens' information rights, information literacy education, and information usage leading to the full engagement into e-society. Specific target is those who are unable to access the Internet due to their inability to buy a computer or to pay for Internet access, or to know how to get information.

\section{Discussion and Analysis}

\section{1 "Information Commons" Model}

Information Commons Model is widely adopted by universities. "Information Commons" means a shared information resource for academic community. It is more than a library, more than a study space, more than an IT center, the whole is greater than the sum of the parts. [17] The Information Commons unites all the facts and figures of the world into a resource available to everyone. Through a massive peer-to-peer network, the Commons enables individuals, non-profits and government agencies to fuse their data together into one database, distributed across many different computers. Sharing data in the Commons is seamless between individuals and organizations, offering easy, flexible data integration and reuse. [18]

The central idea behind IC is the shift of the university mission from teaching to learning, and learning becomes the new organizing principle for the academic libraries. Information literacy reflects a new understanding of learning in which technology and information facilitate the process of learning and the creation of knowledge. The key features of an Information Commons are its external and internal relationships, sense of community, partnerships and collaborations. [19] In IC students have integrated access to printed and electronic information sources in the same place at the same time. The services co-provided by network technicians, librarians, and teachers are seamless creating an ideal condition for shared exploration and ownership of information literacy. 


\subsection{Different IC Applications}

IC consists of three key elements in one place: broadband connected computers, information resources, and professionals. The essence is learning, or "learning by doing". Such places equipped with computers and broadband and professionals provide computers for people who can not afford computers, offer free broadband to those who can not afford Internet fees, and help educate those who lack ICT knowledge. Establishing IC at different organizations such as residents' communities, public libraries, and government agencies can have different characteristics, advantages and drawbacks.

\subsubsection{Residents' Community IC}

In China, residents' committee is the grass roots people's organization, which is closest to every citizen by contacting them day in and day out. The idea of "IC" at this level is a simplified one with the basic elements such as a room with a computer, broadband and one staff. The training and education of community IC focuses on:

- On-line paying of bills (property management, water, electricity, gas, phone and Internet, etc.)

- Health care knowledge (health food, medical care etc.)

- Family management knowledge (marriage issues, children education, elderly caring, etc.)

- Money management knowledge;

- Residential environment protection knowledge

- Domestic service information

- Residential activity information (entertainment \& sports, etc.)

- Job information

\subsubsection{Public Library IC}

The advantages of establishing IC in public libraries are:

- Infrastructure guarantee (broadband, or wireless access to the Internet)

- Equipment guarantee (quantity and quality of computers)

- Software guarantee (free open-source software and e-learning solutions)

- Information resources guarantee (traditional printed materials and digital materials)

- Expertise guarantee (librarians and information professionals)

- Feeling of belonging (sense of community and collaborated learning)

The training and education of community IC focuses on:

- Kinds of information resources

- Library service information

- Knowledge of how to analyze one's information needs

- Knowledge of how to use information resources

- Knowledge of how to evaluate information resources

- Knowledge of how to use information to solve the problem

Knowledge of how to innovate with information 


\subsubsection{Government Agency IC}

Government agencies can create public access rooms in which citizens can visit government websites. This kind of IC focuses on equal access to e-government information and e-services for the purpose of citizen engagement into rule making. The training and education of community $\mathrm{IC}$ focuses on:

- Knowledge of how to use government portal website

- On-line government information

- Government e-service information

- On-line G2C interaction / communication

- E-democracy

- On-line shopping

- Restaurant and traveling information

\subsection{Comparison and Analysis}

A summary of the differences in software and hardware development degree and focus is shown in Table 1.

Table 1. RCIC x PLIC x GAIC

\begin{tabular}{|c|c|c|c|}
\hline $\begin{array}{c}\text { Topic of } \\
\text { Comparison }\end{array}$ & $\begin{array}{c}\text { Residents' } \\
\text { Community IC }\end{array}$ & Public Library IC & $\begin{array}{c}\text { Government } \\
\text { Agency IC }\end{array}$ \\
\hline Infrastructure & Low & High & High \\
\hline Equipment & Low & High & High \\
\hline Software & Low & High & Medium \\
\hline $\begin{array}{c}\text { Information } \\
\text { Resources }\end{array}$ & Low & High & Medium \\
\hline Expertise & Low & High & High \\
\hline $\begin{array}{c}\text { Feeling of } \\
\text { Belonging }\end{array}$ & High & Medium & Low \\
\hline Convenience & High & Medium & Low \\
\hline Focus & E-life & E-learning & E-democracy \\
\hline
\end{tabular}

From the above comparison we can see that the three types are complementary meeting different needs. It's obvious that both hardware and software in residents' community are relatively inadequate and in a poor condition. But people choose the place to go for its vicinity and convenience, for its free atmosphere and familiarity. Several ways can be used to improve its condition. Government can provide regulatory and financial help. Large business in the community can offer funds or equipment. Hundreds of students in the community can work as volunteers to help teach people how to use computers, where to find information, and what decision to make like whether paying the bills online or by visiting an office improving quality of people's lives.

Comparatively, public libraries are the best both in software and hardware condition. However, there is much room for improvement. The highest priority should be given to marketing, promoting, and making full use of the expertise, equipment and information resources. With rich resources like e-learning solutions, open course databases and open access journals as well as expertise in public 
libraries, citizens can learn to teach themselves new knowledge and new skills, thus raising the employment rate, quality of workforce, innovation ability, strengthening the competitiveness of the whole nation.

Different from community or public library IC, government agency IC is more focused on e-government information resources and services, one of the most important parts of e-inclusion. But they have things in common such as Internet access, computers, information resources and information expertise. Priming test of U.S. e-government shows that with educational effort about the issue of egovernment, citizen beliefs can be transformed in a direction positive for beliefs about government effectiveness. [20] With the help of public servants, citizen usage of e-government can be effectively increased, isolation reduced, digital divide bridged, citizen trust in government built up, citizen relationship with government improved, social injustice removed, governance reinforced, sustainable social development guaranteed, and society advanced.

\subsection{Government's Role}

Government, as the highest forum for policy making within its jurisdiction, is playing a vital role in e-inclusion society, and e-government development. It should take the responsibility for the full engagement of every citizen into information society by making appropriate decisions (policies, regulations, and laws), forming right strategies, and having them completely implemented. At the same time, government should control the process, collect, deploy, and disseminate best practices. For instance, at EU level e-Inclusion is part of the third pillar of the i2010 policy initiative, managed by Directorate-General for Information Society and Media of the European Commission. [21]

As far as the above mentioned IC model is concerned, the quickest and most effective way by government to encourage citizen engagement is

- Funding and investing in information infrastructure, providing computers and free Internet access in residents' communities, schools, libraries, and government agencies

- Issuing guiding principles for encouraging citizen's engagement

- Making detailed plans of information literacy education catering to ordinary citizens

- Making it a rule for public servants to take turns serving at residents' communities and government agencies as professional experts

- Guaranteeing the connecting to and free use of all available information resources

- Promoting participation;

- Supervising and evaluating process and outcome

\section{Conclusion}

This paper discusses the applications of "Information Commons" model in order to safeguard the information rights of the disadvantage group. The paper builds on a 
conceptual basis of e-inclusion which I believe should be the strategic choice of esociety. The success and advancement of e-society depend on full engagement of every citizen. By providing computers, Internet access, expertise, and all kinds of information resources to citizens, they can acquire information skills and become information literates. IC model meets all the requirements of helping the needy. Three complementary types of IC have different focuses and characteristics catering to different needs: e-life, e-learning, and e-democracy. Theoretically it is a program of practicality. I hope this paper encourages further empirical research on the operability and better solutions in the field.

\section{References}

1. http://www.e-society_org_mk-key Concepts.mht

2. it.sohu.com/20041104/n222838803.shtml 54K 2007-1-29

3.Darrel M. West, Digital Government Technology and Public Sector

Performance,(Princeton University Press, Princeton and Oxford, 2005), pp. 191-193.

4. Darrel M. West, Digital Government Technology and Public Sector Performance, (Princeton University Press, Princeton and Oxford, 2005), pp. 120.

5, 6, 7. Darrel M. West, Digital Government Technology and Public Sector Performance, (Princeton University Press, Princeton and Oxford, 2005), pp.141-142

8. Darrel M. West, Digital Government Technology and Public Sector Performance, (Princeton University Press, Princeton and Oxford, 2005), pp. 152

9. Darrel M. West, Digital Government Technology and Public Sector Performance, (Princeton University Press, Princeton and Oxford, 2005), pp. 124

10. http://www.arl.org/sc/models/oa.shtml

I1, 12. Michael Geist, Open access: Reshaping rules of research (February 26,2007); http://www.thestar.com-sciencetech

13. National Commission on Excellence in Education, A Nation at Risk (Washington, DC:

U.S. Department of Education, 1983); http://www.ed.gov/pubs/NatAtRisk/risk.html

14, 15. U.S. Department of Education, Office of Educational Technology, Toward A New Golden Age in American Education: How the Internet, the Law and Today's Students Are Revolutionizing Expectations (Washington, D. C., 2004);

http://www.NationalEdTechPlan.org.

16. http://www.e-society_org_mk-key Concepts.mht

17. (http://www.shef.ac.uk/infocommons/

18. (http://www.maya.com/infocommons/

19. Melanie Remy, Information Literacy: The Information Commons Connection, Teaching \& Learning with Technology Conference: Enhancing the Learning Experience (September 17, 2004); http://www.usc.edu/libraries/locations/leavey/news/conference/presentations/ presentations_9-17/USC_Remy.pdf

20. Darrel M. West, Digital Government Technology and Public Sector Performance, (Princeton University Press, Princeton and Oxford, 2005), pp. 13621. http://www.esociety_org_mk-key Concepts.mht 